\title{
Characterization of Potent Phytate Solubilizing Bacterial Strains of Tea Garden Soils as Futuristic Potent Bio-Inoculant
}

\author{
Swayambhu Ghosh ${ }^{1}$, Anupjyoti Goswami ${ }^{1}$, Goutam K. Ghosh ${ }^{2}$ and Prabhat Pramanik ${ }^{*}$ \\ ${ }^{1}$ Department of Soils, Tocklai Tea Research Institute, Tea Research Association, \\ Jorhat-785008, Assam, India \\ ${ }^{2}$ Department of Soil Science and Agricultural Chemistry, Palli Siksha Bhavana, Institute of \\ Agriculture, Visva-Bharati, Sriniketan-731236, West Bengal, India \\ *Corresponding author
}

\section{Keywords}

Phytate, Phytate solubilizing microorganisms, Tea cultivation, Soil available phosphorus

Article Info

Accepted:

12 March 2021

Available Online:

10 April 2021

\section{A B S T R A C T}

Phosphorus $(\mathrm{P})$ is one of the major essential macronutrients for biological growth and metabolism of plants. Tea (Camellia sinensis L) plantation requires adequate amount of $\mathrm{P}$ for the proper yield of tea leaves. However, due to acidic nature of tea growing soils, phosphorus fixation is a common phenomenon. A close look at the different pools of soil $\mathrm{P}$ reveals, major portion of soil $\mathrm{P}$ is present in the form of organic $\mathrm{P}$. Among various members of organic $\mathrm{P}$, myo-inositol hexakisphosphate (or commonly called as phytate) often dominates in soils. This potent sink of $\mathrm{P}$ is unavailable to plants. Only a group of microorganisms can hydrolyze phytate through their phytase enzyme and liberate phosphate, that in turn can contribute to plant nutrition. In this work, 2 phytate solubilizing microorganisms, identified as Bacillus safensis and Bacillus siamensis were isolated from the rhizospheric soils of tea gardens in Assam, India. They were found to show clear halo zone around their colonies on the selective media due to solubilization of Ca-phytate. They were also inoculated in Na-phytate containing Pikovskya's broth. The phosphate concentration varied from 6.2 to $0.8 \mu \mathrm{g}$ $\mathrm{P} \mathrm{ml}^{-1}$ broth during incubation period. Both of them were able to liberate significantly $(\mathrm{p}<0.001)$ higher phosphate in solution through solubilization of phytate present in the media. They were also mass cultured and incubated with tea growing soil under laboratory condition. Both the microbes treated soils showed increase in available P content during the incubation period. Bacillus siamensis treated soil showed a gradual increase in $\mathrm{P}$ content till 80 days of the incubation with a value of $16.5 \pm 0.8 \mathrm{mg} \mathrm{kg}^{-1}$ soil. This microbe was also found to be increasing significantly higher $\mathrm{P}$ in soil than the other microbial strain and control. This work suggests, tea cultivating soils are a natural habitat of phytate solubilizing microorganisms. Also, an indigenous phytate solubilizing microorganism Bacillus siamensis has ability to increase the plant available $\mathrm{P}$ in soil. Thus it can be applied in tea garden soils for efficient phosphorus management. 


\section{Introduction}

Phosphorus $(\mathrm{P})$ is considered to be one of the most important macronutrients required for plant growth (Biswas and Mukherjee, 2001). Being a nutrient demanding crop, tea bushes uptake large amount of macronutrients like nitrogen, phosphorus and potassium every year. Lack of sufficient $P$ availability may affect the metabolism of flavonoids, organic acids and amino acids in the tea leaves and restrict the phosphorylation(Ding et al., 2017) in the plant. To meet the requirement, generally, rock phosphate as fertilizer is applied in tea growing soils (Ruan et al., 2000). However, tea is an acidophilic plant and tea-growing soils are maintained to retain its acidity ( $\mathrm{pH} 4.5-5.5)$. Due to the acidic nature, tea-growing soils are rich in free aluminum, iron (Xie et al., 2001). Under such condition, P-fixation is a common soil related phenomenon and that in turn makes phosphate ions unavailable to plants (Reeve and Sumner, 1970).

Moreover, apart from the fixation with iron or aluminum ions, a large portion of inorganic $\mathrm{P}$ gets converted into organically bound form(Dalal, 1977). The organic $P$ pool in soil may accounts for at least 30\%, and occasionally up to $80 \%$, of the total soil $\mathrm{P}$ (Anderson and Malcolm, 1974). The organic P compounds are largely comprised of phosphate monoesters (may be up to 90\%), with lesser concentrations of phosphate diesters and phosphonates (Condron et al., 1990). It has been found that, most of the phosphate monoesters in soil are present in the form of myo-inositol hexakisphosphate or commonly called as phytate. This phytate may occupy more than $50 \%$ of total soil organic $\mathrm{P}$ (Anderson and Malcolm, 1974).

When rapid depletion of high quality phosphate source and competition for rock phosphates with other industries are making $\mathrm{P}$ fertilization in agricultural soil a serious concern (Bashan et al., 2013), this phytate pool of soil could be a source of supplying $\mathrm{P}$ to the plants. But due to its recalcitrant nature, plants can't uptake phytate. Only a specific group of microorganisms (Ewel,1986; Gerretsen, 1948) capable of secreting exocellular phytase enzymes can hydrolyze phytate in soil. In turn, this hydrolysis results in supply of available phosphorus to the plants.

It is a common tactic to use phosphate solubilizing bacteria for enhancing the availability of $\mathrm{P}$ in soil as an environmentfriendly technique of $\mathrm{P}$ management. The microbes of Bacillus subtilis sp. and Pseudomonas sp. have been well studied as phosphate solubilizing bacteria (Steenhoudt and Vanderleyden, 2000; Trivedi et al., 2005). Rodriguez and Fraga(Rodríguez and Fraga , 1999) have reported about phosphate solubilization of different Pseudomonas sp. like Pseudomonas putida, P. fluorescens and P. fluorescens etc. Different crops like brinjal(Turan et al., 2007), potato and tomato (Faccini et al., 2007; Walpola and Yoon, 2012) have been tested to yield higher with the action of phosphate solubilizing bacteria.

However, often, they are isolated on the basis of their potential to solubilize the phosphate fixed in iron or aluminium (Pikovskaya, 1948). Thus no information on their capability to use the vast phytate-P pool in soil can't be obtained. Previously, workers have isolated phytate solubilizing microorganisms from different soils (Jareonkitmongkol et al., 1997; Tseng et al., 2000), sea sediments (Kim et al., 2003) or other natural environments (Vohra and Satyanarayana, 2002). Till now, several attempts have been made to isolate native soil microbes for solubilizing essential nutrients in different agro-climatic regions. But, studies on phytate solubilizing microbes of tea growing soils are very limited (Rahi et al., 2009). 
Tea growing soil being enriched in high organic matter can contain a large portion of soil $\mathrm{P}$ in organically bound phytate form(Solomon et al., 2002). Only the phytate solubilizing microorganisms have the ability to release inorganic phosphate ions by phytase enzyme-mediated hydrolysis of phytate compounds in soil. The objectives of this study was to focus on isolating suitable phytate-P solubilizing microorganisms from tea growing soil.

\section{Materials and Methods}

\section{Isolation of microorganisms from soil}

Soils were taken from one commercially cultivated tea garden, Bokahola tea estate $\left(26^{\circ}\right.$ $36^{\prime} 59.43^{\prime \prime} \mathrm{N}$ and $94^{\circ} 22^{\prime} 33.74^{\prime \prime} \mathrm{E}$ ) and one organically managed tea garden, Hatikuli tea estate $\left(26^{\circ} 35^{\prime} 8.35^{\prime \prime} \mathrm{N}\right.$ and $\left.93^{\circ} 22^{\prime} 36.70^{\prime \prime} \mathrm{E}\right)$ of Assam, India. The region belongs to subtropical humid climatic zone. The rhizospheric soil from the depth of $15 \mathrm{~cm}$ were sampled from these gardens in several replicates and stored separately in zip locked plastic bags placed in an ice box. In the laboratory, the soils were homogenized thoroughly and used for dilution plate technique (Kumar et al., 2013). Aliquots of serially diluted $\left(10^{-4}\right.$ fold $)$ soil solutions were poured into the modified pikovskaya's media (Pikovskaya, 1948) containing Ca-phytate (Sigma, Germany) as the only source of $\mathrm{P}$ instead of calcium phosphate. The petri plates were incubated at $37 \pm 1{ }^{\circ} \mathrm{C}$ for 48 hours for proper growth of the phytate solubilizing microorganisms (PpSM). After the incubation, phytate solubilizing microorganisms appeared on the media with a clearing zone around their colonies. The isolates were aseptically collected on separate agar slants and purified by repetitive subculturing. The dried soil samples were used for analyzing physico-chemical properties including available nutrient contents and organic carbon (Jackson, 1973).

\section{Phytate solubilizing efficacy}

The purified strains of the isolated phytate solubilizing microorganisms were separately spot inoculated on Ca-phytate enriched modified pikovskaya'sagar media in triplicate. The plates were incubated at $37 \pm 1{ }^{\circ} \mathrm{C}$ for 48 hours. After the incubation, the colonies showed clearing zone around their them. The diameter of the colonies and corresponding clearing zones were measured with help of scale. Using the diameters, the phytate solubilization efficacy (PSE) (Ponmurugan and Gopi, 2006; Premono et al., 1996) was determined for each microbes as:

Phytate solubilization efficacy (PSE)

$$
=\frac{z-C}{c} \times 100
$$

Where diameter of clearing zone in $\mathrm{Z}$ and that of colony is $\mathrm{C}$.

\section{Phytate solubilization assay in broth}

To eliminate the chances of false positive results, the selected microbes were tested for their phytate solubilization capacity in broth solutions. For that, modified pikovskaya's broth media $(\mathrm{pH}=6.2)$ was prepared containing Na-phytate (Sigma, Germany) as the only source of P. 3 days old bacterial cultures were taken. A loop-full culture of each microbe was separately inoculated in the modified pikovskaya's broth.

The flasks were tightly capped and kept for incubation at $31 \pm 1{ }^{\circ} \mathrm{C}$ for 7 days. On the $2^{\text {nd }}$, $3^{\text {rd }}, 4^{\text {th }}$ and $7^{\text {th }}$ day of incubation, the incubating flasks were sampled. The contents were filtered, centrifuged and the supernatant solution was taken for estimation of inorganic phosphate. The concentration of inorganic phosphate was estimated ammonium molybdate reagent (Jorquera et al., 2008) and the blue color intensity was measured at 660 $\mathrm{nm}$ in a spectrophotometer. 


\section{Soil incubation study}

A soil incubation study was conducted with the isolated strains. An arbitrary virgin soil was collected from experimental tea garden of Tocklai Tea Research Institute, Jorhat, Assam, India. The soil was homogenized and sieved to eliminate debris. The microbes were grown in potato dextrose broth for 5 days at room temperature. When the cultures were grown up to exponential growth phase $\left(10^{8} \mathrm{CFU} \mathrm{ml}\right.$ ${ }^{1}$ ), they were taken for mixing with soil. Separately, $75 \mathrm{ml}$ of each microbial culture broth was mixed with $500 \mathrm{~g}$ of soil. The soils were kept in earthen pots. For control, noninoculated broth was mixed with soil. The pots were kept in a completely randomized design (CRD) under laboratory condition receiving regular day light. They were watered to maintain the optimum moisture level. At the interval of every 20 days, the pots were sampled for both the microbes treated and control soil. Sampling was done destructively and in triplicate. The sampled soil was estimated for available phosphorus using $0.003 \mathrm{~N} \mathrm{NH}_{4} \mathrm{~F}$ in $0.025 \mathrm{~N} \mathrm{HCl}$ solution (Bray and Kurtz No. 1) and measured using ammonium molybdate-stannous chloride reagent (Bray and Kurtz, 1945) at $660 \mathrm{~nm}$ in a spectrophotometer.

\section{Phylogenic and biochemical analysis}

The microbes were genetically identified in collaboration with Microbial Type Culture Collection (MTCC), Institute of Microbial Technology (IMTECH) in Chandigarh, India. Genomic DNA were extracted using zymo research genomic DNA extraction kit by following the manufacturer's protocol and 16S rRNA gene was PCR amplified using universal primers27F (AGAGTTTGATCC TGGCTCAG) and 1492R (TACGGYTACC TTGTTACGACTT) (Chen et al., 2015). PCR product was visualized using 1\% Agarose gel. The PCR reaction mixture was prepared as 10x Gotaq buffer $10 \mu \mathrm{l}, \mathrm{MgCl}_{2} 3 \mu \mathrm{l}$, d NTP 1 $\mu 1$, Primer F $1.5 \mu$, Primer R $1.5 \mu$ l, DNA 100 ng, Taq (5U) $0.25 \mu \mathrm{l}$, and then Milli-Q water was added to make up the volume till $50 \mu \mathrm{l}$. The amplified PCR products were purified and sequenced. The phylogenetic tree for the data sets was constructed by the Neighbor-Joining method (Saitou and Nei, 1987) using MEGA6 (Tamura et al., 2013). The evolutionary distances were calculated using the Kimura 2parameter method(Kimura, 1980). The sequences obtained were compared with sequences available in the GenBank database from the National Centre for Biotechnology Information (NCBI). The microbes were studied for their colony and cell morphology under compound microscope. The microbes were also tested for various biochemical properties like Gram staining, carbon source utilization, ONPG test etc.

\section{Statistics}

Before going into any statistical analysis, the data was checked for normality and if required they were transformed to obtain normality (Shapiro and Wilk 1972). The available P concentration data were compared between the treatments (liquid media or soil) using a one-way ANOVA. The test of significance was performed at $p=0.05$. Dunnett's multiple comparison was done in post hoc test for identifying the treatments showing significant changes. The statistical calculations were done in SPSS software package (IBM SPSS 20.0). All the reported data in this study were the arithmetic mean with the standard deviation of three replicates.

\section{Results and Discussion}

\section{Isolation of microorganisms from soil}

The soils of organic tea garden Hatikuli Tea Estate showed higher population of the phytate solubilizing microbe than that of the conventional tea garden, Bokahola Tea Estate on Ca-phytate containing modified 
Pikovskaya's agar media. Both the soils were acidic in nature. The organic carbon content was found to be higher in Hatikuli tea estate soil. The physico-chemical properties of the soils are shown in Table 1.

Using the dilution plate technique, 15 microbial colonies from Bokahola soil and 25 microbial colonies from Hatikuli soil were isolated. Due to larger halo-zone sizes PpSM\#8 from Bokahola soil and PpSM\#46 from Hatikuli soil were selected for further studies. Both the strains showed pale white color of their colonies.

\section{Phytate solubilizing efficacy}

Both the bacterial strains showed growth on the phytate contained media. Around their colonies clear halo-zone was also observed. The strain PpSM\#8 (Ø $1.53 \pm 0.1 \mathrm{~cm})$ showed higher halo-zone diameter than strain PpSM\#46 (Ø $1.2 \pm 0.1 \quad \mathrm{~cm})$ on phytate containing agar media. Also, the colony diameter was found to be higher in case of PpSM\#8 (Ø $1.2 \pm 0.12 \mathrm{~cm}$ ) than that of PpSM\#46 (Ø $1.06 \pm 0.08 \mathrm{~cm}$ ). By calculating the phytate solubilizing efficacy (PSE) it was also found PpSM\#8 has got high values than PpSM\#46. PpSM\#8 showed the PSE value 27.5 whereas PpSM\#46 showed PSE value of 13.2. The picture of PpSM\#8 on Ca-phytate enriched media is shown in Fig. 1. The halozone around the colony can also be seen in the picture.

\section{Phytate solubilization assay in broth}

The bacterial strains were found to be growing in the phytate containing broth. The gradual increase in bacterial clump was visible during the incubation period. Also, the inorganic $\mathrm{P}$ release trend showed the gradual increase over the period in both bacterial strain inoculated treatments (Fig 2). PpSM\#8 as well as PpSM\#46 showed significantly higher $(\mathrm{p}<0.001)$ phosphate content than the control broth during the incubation period. However, the differences in $\mathrm{P}$ release became clearer from $3^{\text {rd }}$ day onwards of the study, and on the $7^{\text {th }}$ day the difference was most prominent. The phosphate concentration was found to vary within the range of 6.2 to $0.8 \mu \mathrm{g} \mathrm{P} \mathrm{ml}{ }^{-}$ ${ }^{1}$ broth during incubation period. Among two bacterial strain the $\mathrm{P}$ release trend was found to be opposite of PSE study. Here, PpSM\#46 showed significantly $(\mathrm{p}=0.036)$ higher $\mathrm{P}$ release than $\mathrm{PpSM} \# 8$ from phytate containing broth on the $7^{\text {th }}$ day of incubation.

\section{Soil incubation study}

The soil used for pot study was taken from a tea garden and showed $\mathrm{pH}$ of 4.6. The study was continued for 140 days and at interval of 20 days the available $\mathrm{P}$ estimation from soils were done. Before initiation of the incubation the soil showed $7.1 \pm 1.8 \mathrm{mg} \mathrm{kg}^{-1}$ available $\mathrm{P}$ content. Both the microbes treated soils showed increase in available $\mathrm{P}$ content during the incubation period (Fig 3). PpSM\#8 treated soil showed a gradual increase in P content till 80 days of the incubation with a value of $16.5 \pm 0.8 \mathrm{mg} \mathrm{kg}^{-1}$ soil. After that, it showed a gradual decrease in $\mathrm{P}$ content. Whereas, PpSM\#46 was found to increase the P content till 80 days, followed by a steady dynamic of available $\mathrm{P}$ for rest of the incubation period. The data shows, the release of $\mathrm{P}$ from soil was dependent on the nature of inoculum. PpSM\#8 was able to liberate significantly $(\mathrm{p}=0.001)$ higher P than both PpSM\#46 and control.

\section{Phylogenic and biochemical analysis}

Identification and genetic characterization (phylogenic analysis) of the microbial strains were carried out by Microbial Type Culture Collection (MTCC), Institute of Microbial Technology (IMTECH) in Chandigarh, India. From the phylogenic analysis (Fig 4) it was found that PpSM\#8 was similar to Bacillus siamensis (MH463552) and PpSM\#46 was similar to Bacillus safensis(MH463557). 
The biochemical analysis of the bacterial strains was performed with help of test kits (Himedia KB 001, 009A, 009B, 009C, DD042). The response of bacterial strains showed that, response of PpSM\#8 for indole utilization and methyl red test was positive but response of PpSM\#46 was negative. However, both the strains were able to utilize citrate, mannitol, dextrose, galactose etc. ONPG test was found to be positive for PpSM\#8 whereas it was negative for PpSM\#46. Both the bacteria were non-motile and did not form hydrogen sulfide as reflected in biochemical tests. A brief result of the biochemical tests is given in Table 2. Both the bacteria were Gram-positive in nature.

In nutrient mobilization and other soil chemical, biochemical processes, plantmicrobe relationship plays a vital role (Schirawski and Perlin, 2018). The population and community structure of soil microorganisms are often dependent on several factors like soil type, climate and cultivated crops.

It has also been observed that different plants cultivated in same soil type may result diverse community structure of bacteria capable of mobilizing soil P (Reyes et al., 2006). In case of tea plantation, Baby (Baby et al., 2001) observed age as well as clone of tea bushes influences the presence of phosphate solubilizing bacteria near the root zone. Phosphorus is one of the key element for tea cultivation. Harnessing the organically bound soil $\mathrm{P}$ through usage of suitable bio-inoculant may become an inevitable tool for P supply to tea plants in near future. Phytate can occupy nearly $50 \%$ of the total soil organic $\mathrm{P}$ and phytate solubilizing microbes can only access this pool through their phytase enzymes. In this study, the soils taken from both the tea estates were found to be natural habitat of phytate solubilizing microbes. Though, the population these microbes differed between the organically managed garden and conventionally managed garden. This may be due to the variation in cultivation practices and soil inputs. Long-term organic cultivation may have influenced the soil health (Mäder $e t$ al., 2002) of Hatikuli soil, resulting higher population of microbes. Most of the isolated strains were bacteria. Previously Jorquera(Jorquera et al., 2008) showed most of the works on phosphate solubilizing microbes report on bacterial strains. That may be due to diverse and higher population of bacteria in soil than fungi (Torsvik et al., 1990). However, observing clear halo-zones, two microbes were finally selected for further studies. For preliminary cooperation in their phytate hydrolyzing ability the pure cultures of PpSM\#8 (Bacillus siamensis) and PpSM\#46 (Bacillus safensis) were spot inoculated on phytate containing agar media.

The PSE value was higher for PpSM\#8 than PpSM\#46. The phytate solubilizing microbe secrets phytase enzymes (Ariza et al., 2013) that cleaves the ester bond and hydrolyzes phytate molecules. Due to solubilization of Ca-phytate the region of solubilization turns clear from opaque. However, Basan(Bashan et al., 2013) argued several false positive responses may misguide the workers by considering halo-zones only as evidence of phytate solubilization by the microorganisms. Richardson (Richardson et al., 2000) referred not all the microbes that can show halo-zone on plate, would be able to grow in liquid media. 
Table.1 General properties of Hatikuli and Bokahola tea gardensoils. The data is represented as mean \pm SD.

\begin{tabular}{|c|c|c|c|c|c|}
\hline & pH (1:2.5) & OC $\left(\right.$ g.kg $\left.^{-1}\right)$ & \multicolumn{3}{c|}{ Available nutrient contents (kg.ha $^{-1}$ ) } \\
\hline & & & $\mathrm{N}$ & $\mathrm{P}_{2} \mathrm{O}_{5}$ & $\mathrm{~K}_{2} \mathrm{O}$ \\
\hline Hatikuli T.E. & $5.32 \pm 0.02$ & $20.4 \pm 4.2$ & $227.46 \pm 25.80$ & $33.72 \pm 4.19$ & $259.35 \pm 15.18$ \\
\hline Bokahola T.E. & $4.8 \pm 0.08$ & $8.7 \pm 1.23$ & $174.54 \pm 19.17$ & $35.78 \pm 6.39$ & $183.3 \pm 10.25$ \\
\hline
\end{tabular}

Table.2 Morphological, physiological and biochemical characteristics of selected phytate solubilizing microbes PpSM\#8 and PpSM\#46, '+' represents the positive response and '-' represents the negative response to the tests.

\begin{tabular}{|c|c|c|c|c|c|}
\hline Test & \multicolumn{2}{|c|}{ Isolate } & \multicolumn{2}{c|}{ Test } & \multicolumn{2}{c|}{ Isolate } \\
\hline Colony morphology & PpSM\#8 & PpSM\#46 & & PpSM\#8 & PpSM\#46 \\
\hline Margins & Diffused & Diffused & Utilization of & Citrate & + \\
\hline Surface & Smooth & Smooth & D-Arabinose & + & + \\
\hline Appearance & $\begin{array}{c}\text { Pale } \\
\text { white }\end{array}$ & White & Dextrose & + & + \\
\hline Cell morphology & & & Fructose & + & - \\
\hline Shape & Rod & Rod & Galactose & - & + \\
\hline Size & Medium & Medium & Glucose & - & + \\
\hline & & & Glycerol & + & + \\
\hline Gram Stain & + & + & Inositol & - & + \\
\hline Motility & - & - & Mannitol & - & - \\
\hline Peptone catabolized & - & - & Mannose & + & + \\
\hline Voges-Proskauer & - & - & Salicin & - & + \\
\hline Methylred test & + & - & Sodium gluconate & - & - \\
\hline Glucose fermetation & + & + & Sorbitol & + & - \\
\hline ONPG & + & - & Sorbose & - & - \\
\hline & & & Sucrose & - & - \\
\hline Formation of & & & & & \\
\hline H2S gas & - & - & & & \\
\hline Indole & - & - & & & \\
\hline Nitrate reductase & - & + & & & \\
\hline
\end{tabular}


Fig.1 Halo-zone formed by a phytate solubilizing bacterial strain PpSM\#8 on Ca-phytate enriched Pikovskaya's agar medium

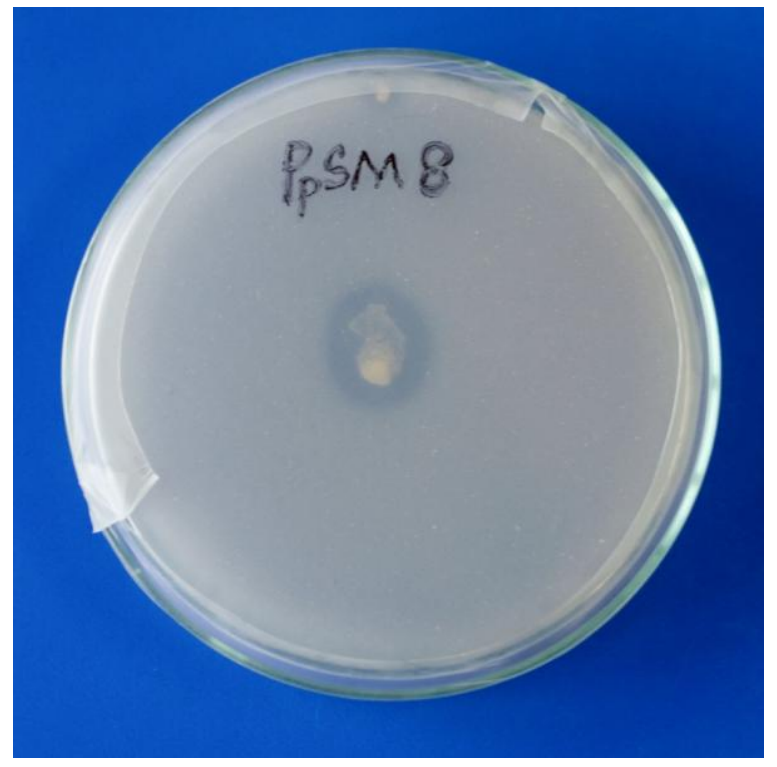

Fig.2 The dynamics of $\mathrm{P}$ release by the microbes in phytate containing broth solution. Different letters represents statistical difference at $\mathrm{p}<0.05$.

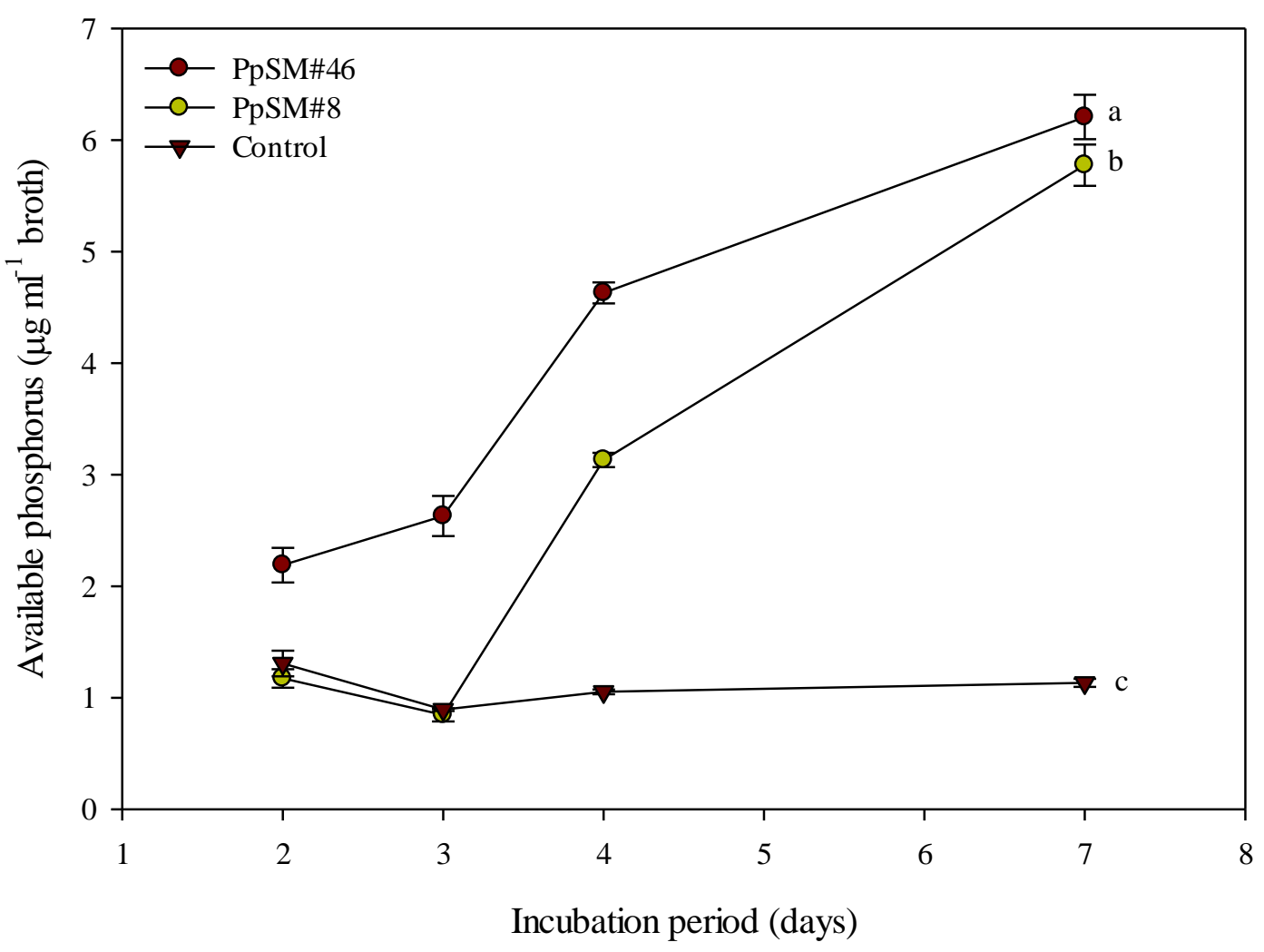


Fig.3 Periodical changes in available phosphorus concentration of soil after application of two selected phytate solubilizing microbial strains. Different letters indicate statistically significant different at $\mathrm{p}<0.05$.

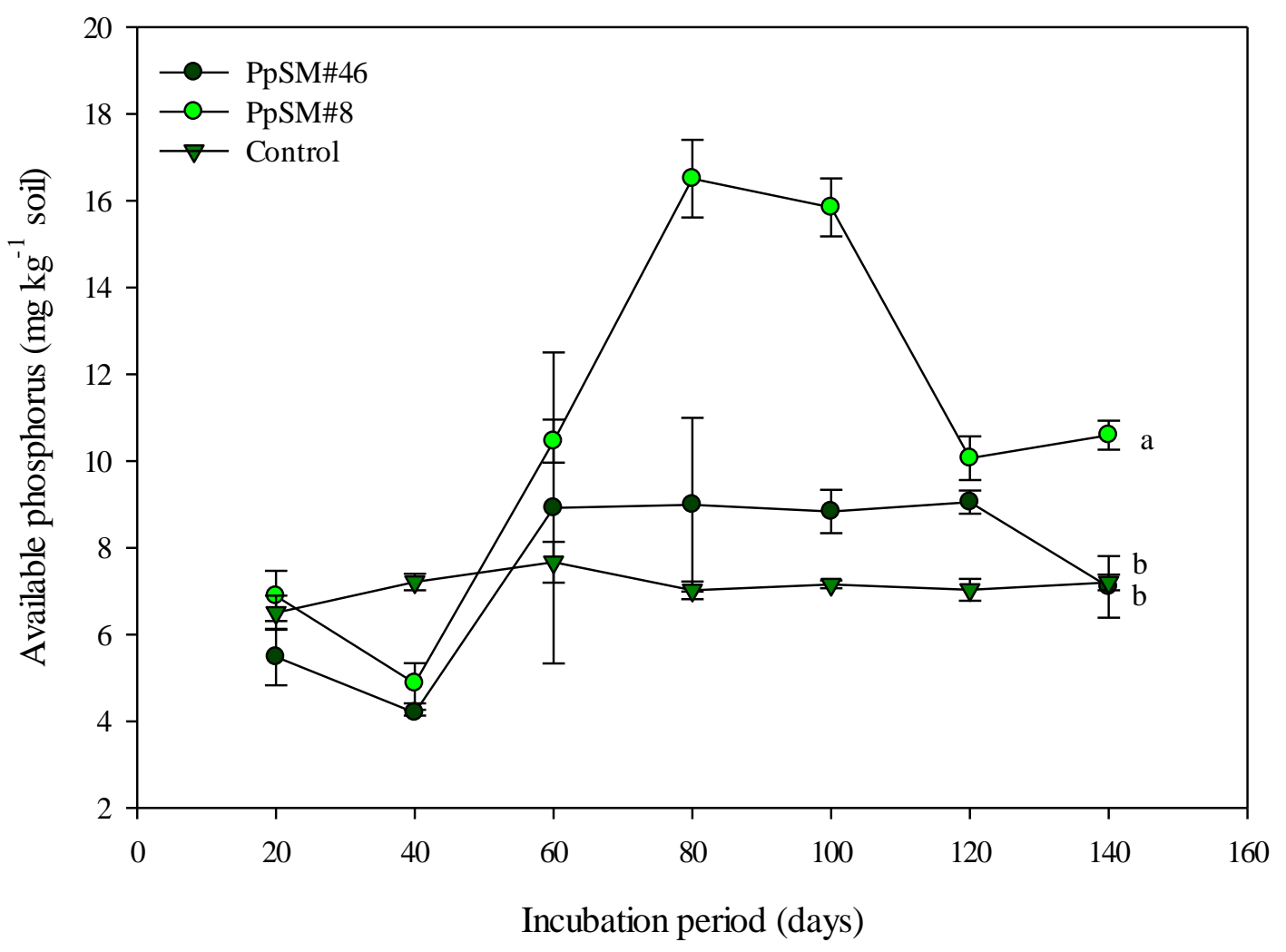


Fig.4 Phylogenetic tree of two bacterial strains under study, (a) PpSM\#8 and (b) PpSM\#46

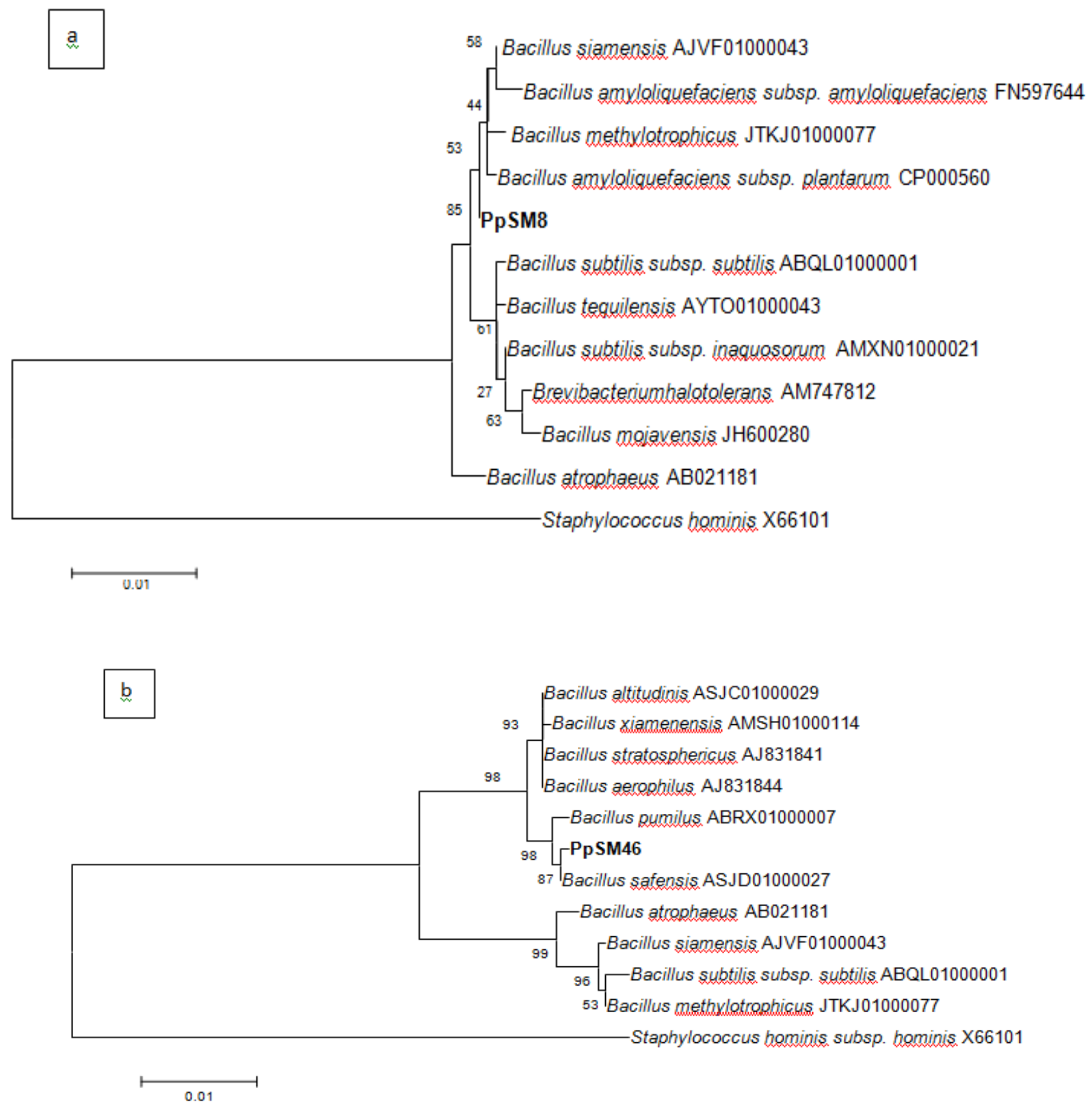

A further level of screening could eliminate the chances of ambiguity. In broth, there was Na-phytate as the sole source of $P$. The microbes hydrolyzed the phytate by means of their enzymes (Bajaj and Wani, 2015). From $3^{\text {rd }}$ day onwards the well grown microbes secreted phytase enzymes in the broth solution. That resulted in rapid increase in the concentration of inorganic phosphate till completion of the incubation. Significant increase in phosphate concentration confirms PpSM\#8 as well as PpSM\#46 were capable of solubilizing phytate. Several studies have been done by microbiologists on phytase of 
different microbes. Various Bacillus sp. (Choi et al., 2001; Powar and Jagannathan, 1982; Shimizu, 1992) including Bacillus siamensis(Verma et al., 2016) have been identified and characterized for their phytase secretion and phytate solubilizing activities. However, for the benefit of plant nutrition it would be necessary to assess these microbes in soil system for their ability to enhance soil available $\mathrm{P}$ through phytate solubilization.

First report of inositol phosphate in soil was came several decades ago (Dyer et al., 1940) after that their importance was realized. However, after the works of Cosgrove (Cosgrove et al., 1970) workers started to show their interest in phytate solubilizing microorganisms to supply plants with phosphorus from soil phytate. The phytate are strongly adsorbed in the humic materials of soil (Mahieu et al., 2002). The microbes release phytase enzymes that can hydrolyze this phytate and liberate phosphate. The accumulation of phytate in soil is strongly influenced by low $\mathrm{pH}$ of soil (Anderson and Arlidge, 1962; Jackman and Black, 1951). Also, being a class of acid phosphatase (Singh et al., 2020), the activity of phytase are higher in acidic soils. In this study, the low $\mathrm{pH}$ and higher organic carbon of the soil used in pot study, typically represents the soils suitable for tea growth. Higher organic carbon also provides the possibilities of storing higher amount of organic phosphate like phytate (Turner et al., 2005). Previously several workers have isolated microbes from soil that showed phytate solubilization in different media (Choi et al., 2001; Kim et al., 2003). However, the reports of in-situ phytate solubilization in soil are rare because of the complexity of soil environment (Nannipieri and Gianfreda, 1998; Quiquampoix et al., 1995). From the notable works George (George et al., 2007) showed how the phytase enzymes of Aspergillus niger and Peniophoralycii behaves in Spodosol and
Alfisol. In this work, both the microbe PpSM\#8 (Bacillus siamensis) and PpSM\#46 (Bacillus safensis) were shown to be increasing the soil available phosphate with time. In broth both of them were found to be hydrolyzing the phytate and release phosphate from it. Thus, it can be assumed that, both Bacillus siamensis and Bacillus safensis were capable of solubilizing the phytate pool in soil and release available phosphate as evident from pot study. However, PpSM\#8 (Bacillus siamensis) was found to be increasing the soil phosphorus significantly than the other inoculum. Thus, for future application in tea growing gardens, this phytate solubilizing microbe Bacillus siamensiscan be applied for better phosphate availability to tea plants.

The soil in tea growing region suffers from phosphorus deficiency. The presence of phytate solubilizing microorganisms in tea rhizospheric soil may be considered as a positive indicator of using them as bioinoculant for beneficial and sustainable tea cultivation. This was a first attempt to isolate and identify phytate solubilizing microorganisms from tea plantations. In this study it was found that one of the isolated microbe Bacillus siamensis has the ability to hydrolyze phytate in agar plate as well as in broth, and also it can improve the available phosphate in soil. Thus it can be concluded this this microbe may be used as bio-inoculant for better phosphorus nutrition of the plants.

\section{Acknowledgment}

The authors are thankful to the Director, Tocklai Tea Research Institute, Jorhat, Assam for providing necessary infrastructure. This work was financially supported by Science and Engineering Research Board (SERB), Department of Science and Technology (DST), Government of India under the project entitled "Possibility of using native phytate solubilizing bacterial strains to enhance $\mathrm{P}$ 
availability by utilizing phytate-P reservoir in tea" (SB/SO/PS/128/2015).

\section{References}

Anderson G, Arlidge E (1962). The adsorption of inositol phosphates and glycerophosphate by soil clays, clay minerals, and hydrated sesquioxides in acid media. Journal of Soil Science 13(2):216-224

Anderson G, Malcolm R (1974). The Nature Of Alkali- Soluble Soil Organic Phosphates. European Journal of Soil Science 25(3):282-297

Ariza A, Moroz OV, Blagova EV, Turkenburg JP, Waterman J, Roberts SM, Vind J, Sjøholm C, Lassen SF, De Maria L (2013) Degradation of phytate by the 6-phytase from hafnia alvei: A combined structural and solution study. PloS one 8(5):e65062

Baby U, Tensingh $\mathrm{B} \mathrm{N}$, Ponmurugan $\mathrm{P}$, Premkumar R (2001) Population dynamics of nitrogen fixing and phosphate solubilising bacteria in tea soil. UPASI Tea Res. Found. Newsletter 10(2):4

Bajaj B K, Wani M A (2015) Purification and characterization of a novel phytase from Nocardia sp. MB 36. Biocatalysis and Biotransformation 33(3):141-149

Bashan Y, Kamnev A A, de-Bashan LE (2013) A proposal for isolating and testing phosphate-solubilizing bacteria that enhance plant growth. Biology and fertility of soils 49(1):1-2

Biswas TD, Mukherjee S (2001) Textbook of soil sciences. Tata McGraw-Hill Education

Bray R H, Kurtz L (1945). Determination of total, organic, and available forms of phosphorus in soils. Soil science 59(1):39-46

Chen Y-L, Lee C-C, Lin Y-L, Yin K-M, Ho C-L, Liu T (2015) Obtaining long 16S rDNA sequences using multiple primers and its application on dioxincontaining samples. BMC bioinformatics 16(18):1-11

Choi Y M, Suh H J, Kim J M (2001) Purification and properties of extracellular phytase from Bacillus sp. KHU-10. Journal of Protein Chemistry 20(4):287-292

Condron L, Frossard E, Tiessen H, Newmans R, Stewart J (1990) Chemical nature of organic phosphorus in cultivated and uncultivated soils under different environmental conditions. European Journal of Soil Science 41(1):41-50

Cosgrove D, Irving G, Bromfield S (1970) Inositol phosphate phosphatases of microbiological origin. The isolation of soil bacteria having inositol phosphate phosphatase activity. Australian Journal of Biological Sciences 23(2):339-344

Dalal R (1977) Soil organic phosphorus. Advances in agronomy. vol 29. Elsevier, pp 83-117

Ding Z, Jia S, Wang Y, Xiao J, Zhang Y (2017) Phosphate stresses affect ionome and metabolome in tea plants. Plant Physiology and Biochemistry 120:30-39

Dyer W, Wrenshall C, Smith G (1940) Isolation of phytin from the soil. American Association for the Advancement of Science Science 91:319-320

Ewel J J (1986) Designing agricultural ecosystems for the humid tropics. Annual review of ecology and systematics:245-271

Faccini G, Garzón S, Martínez M, Varela A Evaluation of the effect of a dual inoculum of phosphate-solubilizing bacteria and Azotobacter chroococcum, in crops of creole potato (papa "criolla"),"yema de huevo" variety (Solanum phureja). In: First International Meeting on Microbial 
Phosphate Solubilization, 2007. Springer, p 301-308

George T S, Simpson R J, Gregory P J, Richardson AE (2007) Differential interaction of Aspergillus niger and Peniophora lycii phytases with soil particles affects the hydrolysis of inositol phosphates. Soil Biology and Biochemistry 39(3):793-803

Gerretsen F (1948) The influence of microorganisms on the phosphate intake by the plant. Plant and Soil:5181

Jackman R, Black C (1951) Solubility of iron, aluminum, calcium, and magnesium inositol phosphates at different $\mathrm{pH}$ values. Soil science 72(3):179-186

Jackson M (1973) L. 1973. Soil Chemical Analysis. Prentic Hall (India) Pvt Ltd New Delhi

Jareonkitmongkol S, Ohya M, Watanabe R, Takagi H, Nakamori S (1997) Partial purification of phytase from a soil isolate bacterium, Klebsiella oxytoca MO-3. Journal of fermentation and bioengineering 83(4):393-394

Jorquera M A, Hernández M T, Rengel Z, Marschner P, de la Luz Mora M (2008) Isolation of culturable phosphobacteria with both phytate-mineralization and phosphate-solubilization activity from the rhizosphere of plants grown in a volcanic soil. Biology and Fertility of Soils 44(8):1025-1034

Kim H-W, Kim Y-O, Lee J-H, Kim K-K, Kim Y-J (2003) Isolation and characterization of a phytase with improved properties from Citrobacter braakii. Biotechnology letters 25(15):1231-1234

Kimura M (1980) A simple method for estimating evolutionary rates of base substitutions through comparative studies of nucleotide sequences. Journal of molecular evolution 16(2):111-120
Kumar V, Singh P, Jorquera M A, Sangwan P, Kumar P, Verma A, Agrawal S (2013) Isolation of phytase-producing bacteria from Himalayan soils and their effect on growth and phosphorus uptake of Indian mustard (Brassica juncea). World Journal of Microbiology and Biotechnology 29(8):1361-1369

Mäder P, Fliessbach A, Dubois D, Gunst L, Fried P, Niggli U (2002) Soil fertility and biodiversity in organic farming. Science 296(5573):1694-1697

Mahieu N, Olk D, Randall E (2002) Multinuclear magnetic resonance analysis of two humic acid fractions from lowland rice soils. Journal of Environmental Quality 31(2):421-430

Nannipieri P, Gianfreda L (1998) Kinetics of enzyme reactions in soil environments. Structure and surface reactions of soil particles:449-479

Pikovskaya R (1948) Mobilization of phosphorus in soil in connection with vital activity of some microbial species. Mikrobiologiya 17:362-370

Ponmurugan P, Gopi C (2006) Distribution pattern and screening of phosphate solubilizing bacteria isolated from different food and forage crops. J Agron 5(4):600-604

Powar V K, Jagannathan V (1982) Purification and properties of phytatespecific phosphatase from Bacillus subtilis. Journal of Bacteriology 151(3):1102-1108

Premono M E, Moawad A, Vlek P (1996) Effect of phosphate-solubilizing Pseudomonas putida on the growth of maize and its survival in the rhizosphere.

Quiquampoix H, Abadie J, Baron M, Leprince F, Matumoto-Pintro P, Ratcliffe R, Staunton S Mechanisms and consequences of protein adsorption on soil mineral surfaces. In: ACS Symposium Series, 1995. vol 602. 
American Chemical Society, p 321333

Rahi P, Vyas P, Sharma S, Gulati A, Gulati A (2009) Plant growth promoting potential of the fungus Discosia sp. FIHB 571 from tea rhizosphere tested on chickpea, maize and pea. Indian journal of microbiology 49(2):128-133

Reeve N, Sumner M (1970) Effects of aluminum toxicity and phosphorus fixation on crop growth on Oxisols in Natal. Soil Science Society of America Journal 34(2):263-267

Reyes I, Valery A, Valduz Z (2006)

Phosphate-solubilizing microorganisms isolated from rhizospheric and bulk soils of colonizer plants at an abandoned rock phosphate mine. Plant and soil 287(1):69-75

Richardson A, Hadobas P, Hayes J (2000) Acid phosphomonoesterase and phytase activities of wheat (Triticum aestivum L.) roots and utilization of organic phosphorus substrates by seedlings grown in sterile culture. Plant, Cell \& Environment 23(4):397405

Rodríguez H , Fraga R (1999) Phosphate solubilizing bacteria and their role in plant growth promotion. Biotechnology advances 17(4):319339

Ruan J, Zhang F, Wong M H (2000) Effect of nitrogen form and phosphorus source on the growth, nutrient uptake and rhizosphere soil property of Camellia sinensis L. Plant and Soil 223(1):65-73

Saitou N, Nei M (1987) The neighbor-joining method: a new method for reconstructing phylogenetic trees. Molecular biology and evolution 4(4):406-425

Schirawski J, Perlin M H (2018) Plantmicrobe interaction 2017-the good, the bad and the diverse.
Multidisciplinary Digital Publishing Institute

Shapiro S S, Wilk M (1972) An analysis of variance test for the exponential distribution (complete samples). Technometrics 14(2):355-370

Shimizu M (1992) Purification and characterization of phytase from Bacillus suhtilis (natto) N-77. Bioscience, Biotechnology, and Biochemistry 56(8):1266-1269

Singh B, Boukhris I, Kumar V, Yadav An, Farhat-Khemakhem A, Kumar A, Singh D, Blibech M, Chouayekh H, Alghamdi Oa (2020) Contribution of microbial phytases to the improvement of plant growth and nutrition: A review. Pedosphere 30(3):295-313

Solomon D, Lehmann J, Mamo T, Fritzsche F, Zech W (2002) Phosphorus forms and dynamics as influenced by land use changes in the sub-humid Ethiopian highlands. Geoderma 105(1-2):21-48

Steenhoudt O, Vanderleyden J (2000) Azospirillum, a free-living nitrogenfixing bacterium closely associated with grasses: genetic, biochemical and ecological aspects. FEMS microbiology reviews 24(4):487-506

Tamura K, Stecher G, Peterson D, Filipski A, Kumar S (2013) MEGA6: molecular evolutionary genetics analysis version 6.0. Molecular biology and evolution 30(12):2725-2729

Torsvik V, Goksøyr J, Daae F L (1990) High diversity in DNA of soil bacteria. Applied and environmental microbiology 56(3):782-787

Trivedi P, Pandey A, Palni L M S (2005) Carrier-based preparations of plant growth-promoting bacterial inoculants suitable for use in cooler regions. World Journal of Microbiology and Biotechnology 21(6):941-945

Tseng Y-H, Fang T, Tseng S-M (2000) Isolation and characterization of a 
novel phytase from Penicillium simplicissimum. Folia microbiologica 45(2):121-127

Turan M, Ataoglu N, Sahin F (2007) Effects of Bacillus FS-3 on growth of tomato (Lycopersicon esculentum L.) plants and availability of phosphorus in soil. Plant soil and environment 53(2):58

Turner B L, Cade-Menun B J, Condron L M, Newman S (2005) Extraction of soil organic phosphorus. Talanta 66(2):294-306

Verma A, Singh V K, Gaur S (2016) Computational based functional analysis of Bacillus phytases. Computational biology and chemistry 60:53-58

Vohra A, Satyanarayana T (2002) Purification and characterization of a thermostable and acid-stable phytase from Pichia anomala. World Journal of Microbiology and Biotechnology 18(7):687-691

Walpola B C, Yoon M-H (2012) Prospectus of phosphate solubilizing microorganisms and phosphorus availability in agricultural soils: A review. African Journal of Microbiology Research 6(37):6600-6605

Xie Z, Ye Z, Wong M (2001) Distribution characteristics of fluoride and aluminum in soil profiles of an abandoned tea plantation and their uptake by six woody species. Environment international 26(5):341346

\section{How to cite this article:}

Swayambhu Ghosh, Anupjyoti Goswami, Goutam K. Ghosh and Prabhat Pramanik. 2021. Characterization of Potent Phytate Solubilizing Bacterial Strains of Tea Garden Soils as Futuristic Potent Bio-Inoculant. Int.J.Curr.Microbiol.App.Sci. 10(04): 470-484. doi: https://doi.org/10.20546/ijcmas.2021.1004.049 